\title{
Review: antiplatelet treatment prevents occlusive vascular events in high risk patients
}

\author{
Antithrombotic Trialists' Collaboration. Collaborative meta-analysis of randomised trials of antiplatelet therapy for \\ prevention of death, myocardial infarction, and stroke in high risk patients. BMJ 2002 Jan 12;324:71-86.

\section{QUESTION: In patients at high risk for occlusive vascular events because of pre-existing disease, how effective is antiplatelet treatment?}

\section{Data sources}

Studies were identified by searching 5 databases and trial registers of the Cochrane Stroke and Peripheral Vascular Disease groups; handsearching journals, abstracts, and meeting proceedings; scanning reference lists of trials and review articles; and contacting pharmaceutical companies and experts.

Sources of funding:

7 funding sources.

For correspondence: Antithrombotic Trialists'Secretariat, Clinical Trial Service Unit, Radcliffe Infirmary, Oxford, UK.

Fax $+44(0) 1865$

558817 .

http://www.ctsu.ox.ac.uk.

\section{Study selection}

Randomised controlled trials were selected if they were available by September 1997 and compared an antiplatelet regimen with a control regimen or with another antiplatelet regimen in patients at high risk $(>3 \% / y)$ for vascular events because of a previous occlusive event or predisposing condition. Included trials had to have adequate allocation concealment and be unconfounded.
Antiplatelet v control treatment for serious vascular events (mean 0.7 to 29 mo of treatment)*

\begin{tabular}{|c|c|c|c|c|c|}
\hline \multirow{2}{*}{$\begin{array}{l}\text { High risk } \\
\text { category }\end{array}$} & \multirow{2}{*}{$\begin{array}{l}\text { Number } \\
\text { of trials }\end{array}$} & \multicolumn{2}{|c|}{ Adjusted event rates } & \multirow[b]{2}{*}{$\operatorname{RRR}(95 \%$ Cl) } & \multirow[b]{2}{*}{ NNT (CI) } \\
\hline & & Antiplatelet & Control & & \\
\hline All trials & 195 & $10.7 \%$ & $13.2 \%$ & $19 \%(16$ to 21$)$ & 41 (36 to 48$)$ \\
\hline Previous MI & 12 & $13.5 \%$ & $17.0 \%$ & $21 \%(16$ to 26$)$ & 28 (22 to 39$)$ \\
\hline Acute MI & 15 & $10.4 \%$ & $14.2 \%$ & $27 \%$ (21 to 32$)$ & 26 (21 to 35$)$ \\
\hline $\begin{array}{l}\text { Previous stroke } \\
\text { or TIA }\end{array}$ & 21 & $17.8 \%$ & $21.4 \%$ & $17 \%(12$ to 21$)$ & 28 (22 to 39$)$ \\
\hline Acute stroke & 7 & $8.2 \%$ & $9.1 \%$ & $10 \%(4.3$ to 16$)$ & 108 (68 to 261$)$ \\
\hline $\begin{array}{l}\text { Other high risk } \\
\text { condition }\end{array}$ & 140 & $8.0 \%$ & $10.2 \%$ & $21 \%$ (16 to 26 ) & 46 (36 to 61$)$ \\
\hline
\end{tabular}

*Serious vascular events were non-fatal MI, non-fatal stroke, or death from a vascular or unknown cause. $\mathrm{MI}=$ myocardial infarction; TIA = transient ischaemic attack. Other abbreviations defined in glossary; RRR, NNT, and $\mathrm{Cl}$ calculated from data in article.

\section{Data extraction}

Trial coordinators were contacted to obtain details about randomisation, allocation concealment, duration of treatment, and follow up. The primary outcome was a serious vascular event (non-fatal myocardial infarction, non-fatal stroke, or death from a vascular or unknown cause).

\section{Main results}

287 trials were included. 197 trials compared antiplatelet treatment with control treatment (195 trials provided vascular event data), and 90 trials compared different antiplatelet regimens (89 trials provided vascular event data). For all high risk patients, antiplatelet treatment led to lower rates of serious vascular events than control treatment $(\mathrm{p}<0.001)$ (table). The rates were also lower for each of 5 high risk categories $(\mathrm{p}<0.001)$ (table) as well as for "other" high risk conditions, including peripheral arterial disease (proportional reduction 23\%, $95 \%$ CI $15 \%$ to $31 \%$ ). An increased risk for major extracranial bleeding occurred with antiplatelet treatment (odds ratio 1.6, CI 1.4 to 1.8). Among trials comparing different antiplatelet regimens, aspirin was better than no aspirin, and daily doses of 75 to $150 \mathrm{mg}$ were at least as effective as higher doses.

\section{Conclusion}

In patients at high risk for occlusive vascular events because of pre-existing disease, antiplatelet treatment reduces the risk for non-fatal myocardial infarction, nonfatal stroke, or death from vascular or unknown causes.

\section{COMMENTARY}

The Antithrombotic Trialists' Collaboration published its first large review in $1994 .{ }^{1}$ In this 2002 update, all studies available by September 1997 have been added. Some of the current results merely strengthen those in the 1994 meta-analysis. The long-standing dispute between American and European strokologists about the relative effectiveness of high dose and low dose aspirin ${ }^{2}$ has finally been resolved: 75 to $150 \mathrm{mg}$ daily is as effective as higher doses in all high risk patient groups.

Much of the new information concerns high risk patient groups that had previously been insufficiently studied. We now know that antiplatelet agents also protect against cardiovascular events in patients with stable angina, intermittent claudication, and atrial fibrillation. Previous documentation concerned improved survival in acute myocardial infarction. Now, it is also well established that antiplatelet drugs have beneficial effects in patients who have unstable angina, undergo coronary angioplasty, or have an acute ischaemic stroke.

This meta-analysis clarifies some issues about the benefits and harm of different antiplatelet agents with different mechanisms of action (aspirin, dipyridamole, clopidogrel, and glycoprotein IIb/IIIa inhibitors). In direct comparisons, although sometimes statistically significant, the differences are small in absolute numbers. For instance, the number needed to treat is about 200/year to prevent one additional cardiovascular event when clopidogrel is compared with aspirin (at a cost that is about 60 times higher). The authors conclude that aspirin, 75 to $150 \mathrm{mg}$ daily, remains the first choice in the long term prevention of cardiovascular events. The net benefits of a combination of 2 different antiplatelet agents are best documented in acute cardiac conditions with exceptionally high risk, such as unstable angina and percutaneous coronary interventions (supported by the results of a recently published trial). ${ }^{3}$

Few trials have lasted $>2$ years. Nevertheless, the documented effects of antiplatelet agents across a wide range of patient groups suggest that low dose aspirin should be given routinely to patients at high or intermediate risk for cardiovascular events (above $2 \%$ per year). In most healthy people, the annual risk is well below $1 \%$.

Kjell Asplund, MD University Hospital, Umea, Sweden

1 Antiplatelet Trialists' Collaboration. Collaborative overview of randomised trials of antiplatelet therapy - I: prevention of death, myocardial infarction, and stroke by prolonged antiplatelet therapy in various categories of patients. BMJ 1994;308:81-106.

Dyken ML, Barnett HJ, Easton JD, et al. Low-dose aspirin and stroke. "It ain't necessarily so". Stroke 1992:23:1395-9.

3 Mehta SR, Yusuf S, Peters RJ, et al. Effects of pretreatment with clopidogrel and aspirin followed by long-term therapy in patients undergoing percutaneous coronary intervention: the PCI-CURE study. Lancet 2001;358:527-33. 